\begin{tabular}{c|c|}
\hline \hline \hline & International Journal of Current Research \\
and Academic Review & and \\
\hline & ISSN: 2347-3215 (Online) Volume 6 Number 4 (April-2018) \\
Journal homepage: http://www.ijcrar.com \\
\hline \hline
\end{tabular}

doi: https://doi.org/10.20546/ijcrar.2018.604.010

\title{
Preferences of Iraqi Women Regarding Mode of Delivery
}

\author{
Ibtisam Abdul Kareem Idan* \\ MBChB, DOG, Al Karamah Teaching Hospital, Iraq \\ *Corresponding author
}

\section{Abstract}

There are many theories about how delivery should be, many factors affecting the preferences of women regarding their mode of delivery, this study aimed to assess the preferences of 428 Iraqi women about what they preferred as a mode of delivery and to evaluate the contributing factors that may affect their choices. Women were enrolled and data collected during $2016-2017$, in Baghdad Iraq from main two hospitals and private clinic. The study concluded that majority of the studied group preferred the vaginal delivery than CS. Preferences of women were significantly affected by their age, education, parity, occupation and income. Previous experience, cultural factor, hospital factors and quality of services among, advices from family or nurses among the main determinant of mothers choices.
\end{abstract}

\section{Article Info}

Accepted: 02 April 2017

Available Online: 20 April 2018

\section{Keywords}

Vaginal delivery, Caesarean section, Preferences, Determinant, rates

\section{Introduction}

The natural way to act at the end of a pregnancy is natural birth and only proceed to perform a cesarean section in certain situations. However, there are many theories about how delivery should be, as well as many doctors in favor of cesarean and many other advocates of natural childbirth. It should be noted that vaginal delivery is a natural process, the woman's body is hormonally and mechanically prepared to be able to carry it out even without medical intervention (Loke and Davies 2015; Loke, Davies, and Li 2015). However, there may be unforeseen events at the time of delivery that require professionals to make the decision to perform a cesarean section such as abnormal heart rate of the baby, position of the baby that hinders natural childbirth, problems of the baby's development such as spina bifida or hydrocephalus, some cases of multiple pregnancy, genital infection of the mother, placenta previa or placental abruption and prolapse of umbilical cord which all considered as indications for cesarean section, in general, any situation that endangers the life of the baby or the mother will be indicative for a cesarean section(Ahmed, Alsheeha, and Alsammani 2013; Molina-Sosa et al., 2004) On the other hand, there are women who prefer to give birth by cesarean because they are afraid of pain or for other reasons, but it must kept in mind that recovery is much worse than with natural birth. In addition, women with caesarean section will need help and assistance from relatives during the first days, either for daily routines or to care for the newborn. In any case, at the time of delivery, health of both the future baby and the mother should be taken into account (Mazzoni et al., 2016). A woman's preference for delivery by caesarean section influenced their subsequent mode of delivery. Asking women in early pregnancy about their preferred mode of delivery provides the opportunity to extend their supports which 
might reduce the rate of elective caesarean section (Rajabi et al., 2016; Zamani-Alavijeh et al., 2017)

Globally, giving birth through natural process, 'vaginal birth' has been widely accepted as the most preferred delivery even when medically indicated caesarean section mode. On the other hand, advances in technology and its adoption in the provision of reproductive health care has resulted in an increase in the number of cesarean deliveries in recent years. This has increased the options preferred mode of administration for mothers and resulted in a significant reduction in mortality and neonatal and maternal morbidity. (Molina-Sosa et al., 2004; Mone et al., 2014). However, each year, 358,000 women die worldwide from pregnancy-related causes, and many women die from obstetric complications (WHO, 2010). Hence, every woman has the human right to the best possible care during pregnancy, childbirth and postpartum to ensure their survival and that of her newborn (COK 2010). Despite this fact, approximately eight million women suffer pregnancy-related complications and over half a million die each year despite these deaths are preventable (WHO, 2013). Many mothers refuse to accept CS because of its associated adverse effects compared with vaginal delivery including high surgery costs, slower recovery of women, increased risk of adverse events in subsequent pregnancies and increasing the rates of complications such as infection, injury to nearby organs, and death (Lumbiganon et al., 2010). On the other hand, the CS is preferred by women who fear the pain associated with vaginal delivery. Preferences of women are reported by type of delivery to be influenced by culture, knowledge of the risks and benefits, and personal and social factors (Nasir 2017).

Cesarean section acceptances is expected to be more difficult. Progress in delivery care, including the use of CS has resulting in significant reduction in mortality and morbidity to both mothers and their neonates. However, evidence to support this belief is limited (WHO, 2010). Nonetheless, spontaneous vaginal delivery is generally regarded as indicative of natural birth or normal for many mothers feel they do not require medical intervention (Fatemeh, 2014). The relevance of this result was confirmed by previous studies, which revealed that despite the increasing caesarean section rate, most women showed more favorable toward vaginal delivery. Preferences of women toward the mode of delivery are affected by different factors including the cultural, religious, financial in addition to medical factors. For instance, almost $66 \%$ of Turkish women preferred vaginal delivery, considered as a natural and acceptable mode of delivery, they considered cesarean delivery as a risky procedure. This in turn increases the rate of home births in Turkey Arikan et al., (2011). In the Muslim community, women prefer home delivery due to privacy which is not fully guaranteed in hospital births, many Muslim mothers refuse to be treated by male staff mentioning the beliefs and practices that increase the motivation for cultural home delivery. Because of this desire for normal delivery, many lose the benefits of hospital-based deliveries as a treatment for any infection associated with birth, providing professional advice on the care of a newborn and postnatal support (Bryanton et al., (2008)). Furthermore, many women believe that spontaneous vaginal delivery is physical, mental, psychological and emotional experience, which gives mothers the strength to cope with childbirth with added confidence as being a natural process expected. Consequently, women associate pain as a natural expectation, adds to her maternal attachment, strength and love. This experience is perceived as an affirmation of successful female role play as expected mother. They sometimes even prefer to deal with the pain using nonpharmacological methods with minimal assistance Maharlouei et al., (2013), From other point of view, cesarean delivery is perceived by some women as a better form of delivery because of its association with birth pangs absence (Lavender et al., 2012). This makes women have no fear of childbirth. They are also encouraged by the safety of the procedure, the speed of the process and the possibility of having a tubal ligation while also positive value associated with this mode of birth. Many have ended up with very nice experience and have enjoyed the process safety (Lavender et al., 2012). Therefore, there are many determinants. Affecting the choices of for the mode of delivery, of these determinants. Socio-demographic factors play a significant role in the mode of delivery options. Maternal age is one of the factors shown to determine the choice of mode of delivery which older mothers prefer vaginal delivery Dharmalingam et al., (2010), Regassa (2011). Accessibility to medical services and trained health care providers in medical services. (Klemetti et al., 2012), Education also has been positively associated with other aspects of maternal care such as prenatal and postnatal care. For example, women with more than primary-level education are more likely to use antenatal care than people without education (Dairo and Owoyokun 2010). (Arthur 2012). Good prenatal care can provide reliable information and support that can influence better choices of modes of delivery at the time of delivery, including delivery plan preparation (Arthur, 2012). Preference for vaginal delivery was also observed among rural women 
(Tsegay et al., 2013). Due to the relatively poor infrastructure such as roads and clinics in rural areas, it is expected that the use of cesarean section for pregnant women will be lower compared to those living in urban areas (Hajian et al., 2015). Urban women are more likely to prefer the use of cesarean delivery mode versus vaginal delivery. Preference for cesarean delivery among urban residents can be attributed to the easy accessibility of health services and access to better information on obstetric care.

Financial constraints and lack of social support structures may limit access to maternal health services quality. Economic stability is an important factor in health care delivery and utilization aspect. Nevertheless, socioeconomic barriers continue to limit access especially among the poor worldwide. A global study conducted in more than 50 countries showed that, on average, more than $80 \%$ of Caesarean births were among wealthy women compared to only $34 \%$ of poor women (Victora et al., 2011). Women who are housewives and have little or no access to resources have no ability to make decisions in their marital homes. They are forced to rely on their mothers' decisions on the law of care during pregnancy and delivery modes.

Lack of resources also limits transportation, even if maternity services are provided free. Lack of income is a known barrier for cesarean delivery.

Religion has also been linked with the use of maternal health services. Kamal (2013) it was shown that religious influence on the mode of delivery was dependent on faith. Among Christians, cesarean delivery is not prohibited, provided it is done under medical advice to improve the life of the mother or to prevent loss of life of the fetus. Among Muslims, it is expected that the birth of normally progressing as planned by God. Cesarean section is not encouraged even with medical advice. Even in emergencies, advocate that should not be done because the life of the mother is the will of God (Abera and Belachew, 2011). This explains the low acceptance of cesarean section among Muslim women.

Culture and values of a society greatly contributes to decisions, behaviors and practices adopted by a community and an individual. For example, vaginal birth mothers value that is celebrated by the community as a sign of femininity, strength and ability to perform the functions most challenging motherhood. It is also seen as an important indicator of passage to motherhood (Spong et al., 2012).
Factors related to the hospital also influence the decision of mothers in the use of services such as the type of delivery. The characteristics of providing health care services make a significant contribution to maternal decisions for the type of delivery. Once the mother has chosen the right service provider, she made sure good professional responsible decisions in which the alternative delivery method would have been chosen as a last resort option to the satisfaction of the mother. Tian et al., (2014) Liu et al., (2013).

Knowledge, attitudes and perceptions of mothers varies in different types of delivery modes. (Yazdizadeh et al., 2011). The most common reason for maternal request CS was the fear of pain (Fatemeh et al., 2014). Increased maternal knowledge on methods of pain relief during labor and provide equipment and personnel certified to optimize obstetric anesthesia in both public and private hospitals can lead to the reduction of maternal fear of pain and encourage more mothers prefer vaginal delivery (Yuen et al., 2014).

Despite the many studies conducted elsewhere with a good perception of preferences for modes of delivery, most of these studies are conducted in developed countries with limited publication in developing countries, therefore, the current study tried to assess the preferences of Iraqi women toward the mode of delivery and the factors that influence their options.

\section{Materials and Methods}

This was a cross-sectional survey included 428 Iraqi women, enrolled in the study during the period from June 2016 to august 2017. The participated women were mothers after childbirth who gave their informed consent to participate in the study who were attended the outpatients clinic of the Gynecology and Obstetrics department at the included two hospitals in Bghdad during the study period; Shaheed Mohammad Baqir AlHakeem Hospital, and AlKarama teaching Hospital. Additionally some participants were clients of the private clinic of the researcher. All official agreement, and women's verbal consent were obtained' prior to initiation of the study and enrollment of participants.

The sample size was calculated according to the standard equation for cross-sectional studies:

$N=\frac{Z^{2} \times P(1-P)}{d^{2}}($ Mohamad et al, 2013) 
Where $(\mathrm{N})$ is the required sample size, $\mathrm{Z}$ is the standard deviation corresponding to $95 \%$ level of confidence, $\mathrm{P}$ is expected proportion (that can be obtained from same studies), and $\mathrm{d}$ is precision. in our study we proposed equal proportions of women that prefer either mode of delivery, $(\mathrm{P}=50 \%)$ this assumption to obtain the larger sample size, $\mathrm{Z}$ is a constant for the $95 \%$ confidence which is equal to (1.96) and precision (d) was set at 0.05). Applying the equation revealed that the required sample was 384 additional $15 \%$ were added, to cover the non-response aire. So that the total calculated sample was 441, approximated to 450 , however, despite the higher response rate but still 24 women refused, giving a response rate of 93\%, and the net sample size was 426 women, and this sample size was sufficient to achieve the minimum required for data analysis

\section{Inclusion and exclusion criteria}

All mothers after childbirth and who gave their informed consent to participate in the study. While mother who were non-Iraqi or non-Arabic speaking, failed to give the consent or refuse to participate in the study were excluded from the study.

Data collected by direct interview with the study participant using pre constructed data collection sheet (questionnaire) which gathered information about demographic characteristics of mothers, mode and place of delivery that they most preferred, infant gender, socioeconomic status, reasons for their choice of the mode of delivery. Data were analyzed using the sttistical package for social sciences (SPSS) version 22, statistical procedures and tests were applied accordingly. Level of significance was set at 0.05 .

\section{Results and Discussion}

There were 428 women enrolled during the study period with a mean age of 28.3 years, the demographic characteristics are shown in (Table1). Among the studied group, majority, (79\%) preferred to deliver by normal vaginal delivery (NVD), and the remaining $21 \%$ were preferring CS, (Figure 1).

The preferred mode of delivery was significantly associated with the age of women aged 21 - 40 years were more preferred NVD than CS delivery, than younger or older women $(\mathrm{P}<0.001)$. Women who had 1 4 parities, were more likely to prefer the NVD while primigravida and those with more than 4 parities, $(\mathrm{P}<$ 0.001). Additionally, housewives were significantly associated with the preferring of NVD, $(\mathrm{P}<0.001)$. In adequate income was also associated with the preferring of NVD than CS, $(\mathrm{P}<0.001)$. The options and decision of mothers about their preferred mode of delivery was not affected by the gender of their neonates, $(\mathrm{P}>0.05)$, these findings are shown in (Table 2). The reasons contribution and effect of these factors on the mother choices for either mode delivery were multifactorial; on the top of the list previous experience represented the more frequent reason, $62.7 \%$, of women said that their option was mainly based on their previous experience with the mode of delivery. Furthermore, 55.6\% claimed that their choice was depend on the decision of the husband or the family. Hospital-related Factors contributed for $49.6 \%$ of all reasons that affect mother choice or decision about the preferred mode of delivery. Advice from family members or relatives responsible for $44.3 \%$ of the decisions of mothers about their preferred mode of delivery. Financial and economic reasons for $28.2 \%$ Medical causes for $24.2 \%$, Cultural values for $22 \%$, Perceived delivery services quality for $19.3 \%$, Nurses or midwives advice contributed for $13.6 \%$ and advice from friends affected the options of $8 \%$ of the women in the study, (Table 3).

The study found that younger women (age $\leq 20$ years) and women older than 40 years, have higher CS rate than those aged the age group between $21-40$ This finding is similar to a study in Nigeria, which showed higher rates CS delivery among younger women (Envuladu et al., 2013). The high prevalence of CS among younger women may be due to increased birth complications associated with pregnancy at an early age and underdeveloped reproductive systems.

Regarding the level of education, the study found that the rate of CS increased with increasing level of education. This finding was also reported by Klemetti et al., (2012) which documented that the acceptance of CS increased among mothers with higher education. This could be due to the fact that educated mothers have the ability to access and use appropriate information to support their delivery decisions easily.

Our study showed that VD was common among women with higher parity, while CS is common among primigravida. This result is in agreement with a study by Tsegay et al., (2013) in which parity was associated with a higher probability for VD deliveries. Women with higher parity, especially those with VD successful deliveries have increased confidence. They have less fear of pain and risk pregnancy outcomes associated with CS. 
Fig.1 Distribution of the studied group according to their preferred mode of delivery

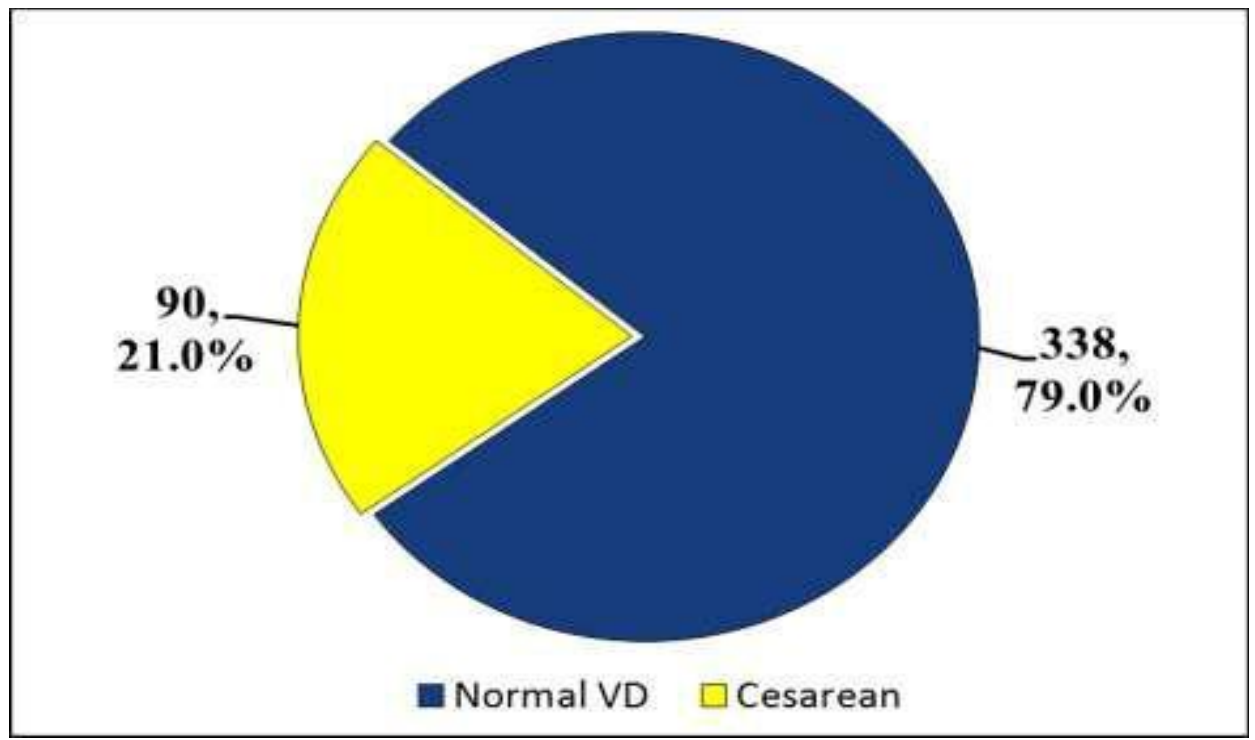

Table.1 Demographic characteristics of the studied group $(n=428)$

\begin{tabular}{|c|c|c|c|}
\hline Variable & & No. & $\%$ \\
\hline \multirow[t]{4}{*}{ Age in years } & $\leq 20$ & 92 & 21.5 \\
\hline & $21-30$ & 178 & 41.6 \\
\hline & $31-40$ & 112 & 26.2 \\
\hline & $>40$ & 46 & 10.7 \\
\hline \multirow[t]{4}{*}{ Parity } & Primigravida & 104 & 24.3 \\
\hline & $1-2$ & 185 & 43.2 \\
\hline & $3-4$ & 103 & 24.1 \\
\hline & $>4$ & 36 & 8.4 \\
\hline \multirow[t]{2}{*}{ Job } & Housewife & 255 & 59.6 \\
\hline & Employed & 173 & 40.4 \\
\hline \multirow[t]{4}{*}{ Education level } & Illiterate/read and write & 93 & 21.7 \\
\hline & Primary & 110 & 25.7 \\
\hline & Secondary & 143 & 33.4 \\
\hline & Institute or higher & 82 & 19.2 \\
\hline \multirow[t]{2}{*}{ Income } & Adequate & 192 & 44.8 \\
\hline & Inadequate & 236 & 55.2 \\
\hline \multirow{2}{*}{ Mode of current child } & Vaginal delivery & 261 & 61.0 \\
\hline & Cesarean section & 167 & 39.0 \\
\hline \multirow{2}{*}{$\begin{array}{l}\text { Gender of current } \\
\text { child }\end{array}$} & Male & 211 & 49.3 \\
\hline & Female & 217 & 50.7 \\
\hline
\end{tabular}


Table.2 Demographic characteristics and preferred mode of delivery of the studied group

\begin{tabular}{|c|c|c|c|c|c|c|}
\hline \multirow{3}{*}{ Variable } & & \multicolumn{4}{|c|}{$\begin{array}{l}\text { Preferred mode of } \\
\text { delivery }\end{array}$} & \multirow{3}{*}{ P. value } \\
\hline & & \multicolumn{2}{|c|}{$\begin{array}{l}\text { Vaginal delivery } \\
\qquad(\mathbf{N}=338)\end{array}$} & \multicolumn{2}{|c|}{$\begin{array}{l}\text { Cesarean section } \\
(\mathbf{N}=90)\end{array}$} & \\
\hline & & No. & $\%$ & No. & $\%$ & \\
\hline \multirow[t]{4}{*}{ Age in years } & $\leq 20$ & 56 & 60.9 & 36 & 39.1 & \multirow{4}{*}{$<0.001$} \\
\hline & $21-30$ & 147 & 82.6 & 31 & 17.4 & \\
\hline & $31-40$ & 102 & 91.1 & 10 & 8.9 & \\
\hline & $>40$ & 33 & 71.7 & 13 & 28.3 & \\
\hline \multirow[t]{4}{*}{ Parity } & Primigravida & 74 & 71.2 & 30 & 28.8 & \multirow{4}{*}{$<0.001$} \\
\hline & $1-2$ & 162 & 87.6 & 23 & 12.4 & \\
\hline & $3-4$ & 88 & 85.4 & 15 & 14.6 & \\
\hline & $>4$ & 14 & 38.9 & 22 & 61.1 & \\
\hline \multirow[t]{2}{*}{ Occupation } & Housewife & 230 & 90.2 & 25 & 9.8 & \multirow{2}{*}{0.001} \\
\hline & Employed & 108 & 62.4 & 65 & 37.6 & \\
\hline \multirow{4}{*}{$\begin{array}{l}\text { Level of } \\
\text { education }\end{array}$} & Illiterate/read and write & 84 & 90.3 & 9 & 9.7 & \multirow{4}{*}{0.001} \\
\hline & Primary & 92 & 83.6 & 18 & 16.4 & \\
\hline & Secondary & 110 & 76.9 & 33 & 23.1 & \\
\hline & Institute or higher & 52 & 63.4 & 30 & 36.6 & \\
\hline \multirow[t]{2}{*}{ Income } & Adequate & 136 & 70.8 & 56 & 29.2 & \multirow{2}{*}{0.003} \\
\hline & Inadequate & 202 & 85.6 & 34 & 14.4 & \\
\hline \multirow{2}{*}{$\begin{array}{l}\text { Gender of } \\
\text { current }\end{array}$} & Male & 163 & 77.3 & 48 & 22.7 & \multirow{2}{*}{0.46} \\
\hline & Female & 175 & 82.9 & 42 & 19.9 & \\
\hline
\end{tabular}


Table.3 Contributing factors affecting the mothers options for the mode of delivery

\begin{tabular}{|l|c|}
\hline Factor & Contribution (\%) \\
\hline Previous experience & $62.7 \%$ \\
\hline Decision of husband or family & $55.6 \%$ \\
\hline Hospital-related Factors & $49.6 \%$ \\
\hline Advice from family members and relatives & $44.3 \%$ \\
\hline Financial and economic causes & $28.2 \%$ \\
\hline Medical causes & $24.2 \%$ \\
\hline Cultural values & $22.0 \%$ \\
\hline Perceived delivery services quality & $19.3 \%$ \\
\hline Nurses or midwives advice & $13.6 \%$ \\
\hline Advice from friends & $8.0 \%$ \\
\hline
\end{tabular}

The type of birth had significantly associated with the categories of income, women with adequate income were more likely preferred CS than VD, while those with lower income (Inadequate) prefer to get VD. This result agreed the findings of Dagne (2010), who found income levels to influence access to special delivery options CS.

This finding is also compatible with a global study conducted in more than 50 countries showed that more than $80 \%$ of births were Caesarean among rich women compared to only $34 \%$ for poor women (Victora et al., 2011).

This finding can be attributed to the availability of free delivery services in public hospitals. However, among these Muslim communities, it was clear that women are dependent on their spouses and close relatives that limit the discretion of highly delivery options. This result the crucial role of reducing economic vulnerability lies through opportunities for education and financial literacy among women as a measure of improved delivery and outcomes of health of the general woman requires informed decision-making (Chanza et al., 2012).
In the present study, housewives were significantly preferred VD than employed women. This is explained by the finding that, in many cases, household income is the main benchmark for the wealth of woman as opposed to personal income.

In particular, most women are housewives as it had greatly promoted the culture and trust spouse or family wealth (Kamal, 2013, Abera and Belachew, 2011)

Gender of the newborn did not affect the decision of women to choose either mode of delivery. Regarding the main determinant factors that affect the decision of the mother to choose the mode of delivery or to prefer one mode than another, the current study found that the contributing factors in the following sequence ; previous experience $62.7 \%$, decision of the husband or the family $55.6 \%$, Hospital-related Factors, 49.6\%, advice from family members or relatives responsible for $44.3 \%$, financial and economic reasons, Medical causes, Cultural values, Perceived delivery services quality Nurses or midwives advice contributed, and the least effect was due to advice from friends only $8 \%$. 
These findings were almost similar to that of previous studies conducted in other countries Mokua (2014), some cultural women labeling values that cannot give birth normally as women 'failed', increasing CS rejection rate leading to high mortality and morbidity of mothers and their newborn. This is supported by Yazdizadeh et al., (2011) who agreed that beliefs and perceptions about options for women's health is largely linked to prevailing social norms and values and culturally acceptable.

The distance from home to health facility is an important hospital related factor, Aberese-Ako et al., (2015), who reported that influences distance delivery options by improving availability and access to health services. The perceived quality of care mainly influence mode of delivery. The number of deliveries both VD and CS increased the perception of improved quality of care delivery Kitui et al., (2013). Women were of the opinion that the quality of delivery services is significantly and continues to improve in hospital as a result of increased skilled deliveries and the CS acceptance. Improving the perceived quality of care of women ensures that the facility has the capacity of staff and resources to carry out safely and successfully CS. (Liu et al., (2013). Additional staff friendliness is an important building perceived quality of service not only, but also the choice of mode of delivery Yazdizadeh (2011),

The study found that respondents did not have enough knowledge about care delivery, risk and related problems undermining their ability to make informed decisions and sound. In the present study, women associated CS potential for infertility and limited possibilities of giving birth normally for future deliveries. This finding of the study was similar to that of Fatemeh et al., (2014) in which women with CS risks associated infertility. This explains the increase in CS CS rejection rate even for life-saving interventions that the risk of any baby or mother indicated. Consequently, a substantial proportion of women, do not attend ANC because they are ignorant of its importance in the safe delivery. In addition, many women attending ANC do not get enough advice and support midwives due to time limited interaction between patient and provider health staff. This finding was supported by a study by Ruckley et al., (2012) and Fatemeh et al., (2014)

Women in the study have found that attitude and practices affecting negative delivery options. inadequate knowledge has been linked to negative and bad practices toward choosing delivery methods especially use of CS attitudes. This finding was similar to that of Yazdizadeh et al., (2011) in which women were reported attitudes and practices to influence individual beliefs and perceptions towards delivery options. education and creating awareness of women is useful to help women adopt a positive attitude towards delivery options.

The study concluded that women perceive VD as the most natural physiological process, and a sign of femininity. CS is the least used method. However, because of the growing medical breakthrough, cesarean delivery is becoming an acceptable mode of administration and frequent especially among the educated, richer and more young people living in urban areas that are highly influenced by the values of Westernization. However, CS acceptance rates among Iraqi women remained low. Further studies are highly suggested on the national level including larger sample size for more investigation of the factors associated with preferences of women regarding mode of delivery.

\section{References}

Abera, M., Gmariam, A. and Belachew, T. (2011) Predictors of service utilization in the Arsi safe delivery area in the southeast Ethiopia. Ethiop Journal of Health Sciences. 21, 101-113.

Ahmed, Salah Roshdy, Muneera A. Alsheeha, and Mohamed Alkhatim Alsammani. 2013. "Risks and Indications for Cesarean Sections in Primiparous Women: A Case-Control Study." Annals of Tropical Medicine and Public Health 6(5): 541-44.

Arikan, DC, Özer, A., Arikan, I., Coskun, and Kiran A., H., (2011) personal preference obstetricians Turkey for mode of delivery and attitude toward cesarean delivery on maternal request. Archives of Gynecology and Obstetrics, 284 (3), 543-549.

Arthur, E., (2012) Wealth and prenatal care use: Implications for the use of maternal health care in Ghana. health economics review. 2 (1), 65-78.

Bryanton, J. Gagnon, AJ, Johnston, C. and Hatem, M., (2008) Predictors of perception of hildbirth experience women. Journal of Obstetric, Gynecologic and Neonatal Nursing. 37 (1), 24-34.

Chanza, D., Chirwas, E., Maluwa, A. and Masache, G. (2012) Factors affecting the choice of deliveries in Malawi. African Journal of Obstetrics and Women's Health. 6 (3), 98-105.

Dagne, E. (2010). Role of socio-demographic factors in the use of maternal health services in Ethiopia. $\mathrm{PhD}$, Umeå International School of Public Health, 8 (4), 232-9.

Dairo, M. and Owoyokun, K. (2010). Factors affecting 
the utilization of antenatal care services in Ibadan, Nigeria. Benin Journal of Postgraduate Medicine. 12 (1), 132-152.

Dharmalingam, A., Navaneetham, K. Krishnakumar, CS (2010) The nutritional status of mothers and low birth weight in India. Magazine maternal and child health. 14 (2), 290-298.

Envuladu, A., Agbo, A., Lassa, S., Kigbu, H. and Zoakah, A. (2013) Factors determining the choice of a place of delivery among pregnant women in the village of Russia north of Jos, Nigeria: MDGs 4 and 5. International Journal of Medicine and Biomedical Research. 2 (1), 23-27.

Fatemeh G., Azadeh A., A. Eznollah Farideh S., Mina M., Z. Shahrzad, Farah F. and Y. Fakhr-al-Molouk (2014). Women's knowledge and attitude towards the type of delivery and frequency of caesarean request of the mother of six public and private hospitals in Tehran, Iran. J. Obstet. Gynaecol. Res. 17 (5), 43-57.

Hajian, S., Shariati, M., Najmabadi, KM, Yunesian, M. and Ajami, MI (2015).Use of the extended parallel process model (EPPM) to predict the intention of Iranian women by vaginal delivery. Journal of Transcultural Nursing. 26 (3), 234-243.

Kamal, S. (2013) Preference for institutional delivery and cesarean Explosionladesh. Journal of Health, Population and Nutrition. 31 (1), 96-107.

Kitui, J., IAT, S. Davey, G. (2013) Factors influencing place of delivery for women in Kenya: an analysis of demographic and health survey Kenya 2008/2009. BMC pregnancy and childbirth. 13 (1), $1-18$.

Klemetti, R., Che, X. Gao, Y., Raven, J., Wu, Z., Tang, S. and Hemminki, E. (2010) delivery section caesarean primiparous women in rural China: an emerging epidemic. American Journal of Obstetrics and Gynecology, 202 (1), 65-E1.

Lavender, T., Hofmeyr, G. Neilson, P., Kingdon, C. and Gyte, G. (2012) caesarean section-term medical reasons. The Cochrane Library.

Liu, NH, Mazzoni, A., Zamberlin, N., Colomar, M., Chang, OH, Arnaud, L., Althabe, F. and Belizán, JM, (2013). Preferences for the type of delivery in Argentine nulliparous women: a qualitative study. Reproductive health. 10 (1). 1-12.

Loke, Alice Yuen, and Louise Davies. 2015. "Factores Que Influyen En La Decisión de Que Las Mujeres En Su Modo de Entrega: La Creencia Modelo de Salud.": 1-12.

Loke, Alice Yuen, Louise Davies, and Sau Fun Li. 2015. "Factors Influencing the Decision That Women
Make on Their Mode of Delivery: The Health Belief Model." BMC Health Services Research 15(1): 112.

Lumbiganon, P., Laopaiboon, M., Gulmezoglu, A., Souza, JP, Taneepanichskul, S., Ruyan, P., Attygalle, E., Shrestha, N., Mori, R., Nguyen, D. (2010) Method of delivery and pregnancy outcomes in Asia: WHO global survey on maternal and perinatal health in 2007-2008. Lancet. 375, 490-499.

Maharlouei, N., Rezaianzadeh, A., Hesami, E., Moradi, F., Mazloomi, E., Joulaei, H., Khodayari, M. and Lankarani, K. (2013) The preference of Iranian women to have a normal vaginal or cesarean delivery. Journal of research in the medical sciences: the official journal of Isfahan University of Medical Sciences. 18 (11), 943-961.

Mazzoni, Agustina et al., 2016. "Women's Preferences and Mode of Delivery in Public and Private Hospitals: A Prospective Cohort Study." BMC pregnancy and childbirth 16: 34. http://dx.doi.org/10.1186/s12884-016-0824-0.

Mohamad Amin Pourhoseingholi, Mohsen Vahedi, corresponding author and Mitra Rahimzadeh. (2013), Sample size calculation in medical studies, Gastroenterol Hepatol Bed Bench. 6(1), pp 14-17.

Mokua, J. (2014) Factors influencing labor practices among pregnant women in Kenya: a case of Wareng'District UasinGishu County, Kenya. International Journal of Innovation and Scientific Research. 10 (1), 50-58.

Molina-Sosa, A., H. Galvan-Espinosa, J. GabrielGuzman, and R. F. Valle. 2004. "Self-Inflicted Cesarean Section with Maternal and Fetal Survival." International Journal of Gynecology and Obstetrics 84(3): 287-90.

Mone, Fionnuala et al., 2014. "Predicting Why Women Have Elective Repeat Cesarean Deliveries and Predictors of Successful Vaginal Birth after Cesarean." International Journal of Gynecology and Obstetrics 126(1): 67-69.

Nasir, Nadia A. 2017. "Knowledge and Attitude of Pregnant Women towards Modes of Delivery in an Antenatal Care Clinic in Baghdad." 59(1): 25-30.

Rajabi, Abdolhalim et al., 2016. "Non-Medical Factors Affecting Antenatal Preferences for Delivery Route and Actual Delivery Mode of Women in Southwestern Iran." Journal of Maternal-Fetal and Neonatal Medicine 29(22): 3622-28.

Regassa, N. (2011) use of prenatal and postnatal services in southern Ethiopia: a study based on the population. African health sciences, 11 (3): 87-98.

Ruckley, C., Fowkes, G. Bradbury, W. (2012) venous 
disease: epidemiology, management and delivery of care. Springer Science and Business Media.

Tian, X., Wu, J., Li, B., Qin, M. and Qi, J., (2014) Appearance of caesarean and related factors in 40 counties in China from 1978 to 2010. Zhonghuayu fang yixuezazhi [Chinese Journal of Preventive Medicine]. 48 (5), 391-395.

Tsegay, Y., Gebrehiwot, T., Goicolea, I., Edin, K., Lemma, H. and San Sebastian, M. (2013) Determinants of prenatal care utilization and delivery in Tigray, Ethiopia: A cross - Sectional study. International Journal of equity in health. 12 (1), 1-19.

Victora, C. Aquino, M., Carmo Leal do, M., Monteiro, C, Barros, F. and Szwarcwald, C. (2011) Maternal and child health in Brazil: progress and challenges. The Lancet, 377 (9780), 1863-1876.

WHO (2010) Countdown to 2015 Decade Report (20002010): Balance of maternal, newborn and child survival. World Health Organization: UNICEF, http://www.who.int.

WHO (2013) Trends in cesarean section by country and wealth quintile: cross-sectional surveys in South Asia and sub-Saharan Africa. World Health Organization. Available in: http://www.who.int

Yazdizadeh B, Nedjat S, Mohammad K, Rashidian A Changizi N, Majdzadeh R. (2011). Cesarean rate in Iran, multidimensional approaches to behavior change providers: A qualitative study. BMC Health Services Research. 11.159-171.

Yuen, J., Painter, I., Abraham, L., Melian, M. and Denno, DM, (2014). A comparison of trends in cesarean delivery in Paraguay between 1995 and 2008. International Journal of Gynecology and Obstetrics. 126 (3), 26.

Zamani-Alavijeh, Fereshteh, Parvin Shahry, Maryam Kalhori, and Marzieh Araban. 2017. "Pregnant Women's Preferences for Mode of Delivery Questionnaire: Psychometric Properties.” Journal of Education and Health Promotion 6(1): 20.

\section{How to cite this article:}

Ibtisam Abdul Kareem Idan. 2018. Preferences of Iraqi Women Regarding Mode of Delivery. Int.J.Curr.Res.Aca.Rev. 6(4), 65-74. doi: https://doi.org/10.20546/ijcrar.2018.604.010 